\title{
DE SYSTEMATIEK DER SYNTAXIS.
}

$\S 1$. Algemeene inleiding. $-\S 2$. De aanleiding tot de volgende beschouwingen. § 3. Innerlijke taalvorm. $-\S 4$. De hoofdstukken der syntaxis.

$\S 5$. De categorieën-leer. $-\S 6$. Geen scherpe grenzen tusschen de categorieën. $-\S 7$. De categorie der oorzakelijkheid. $-\S 8$. De categorie der modaliteit.

$\S 9$. De semasiologische classificatie der werkwoorden. $-\S 10$. Geen scherpe grenzen tusschen de semasiologische groepen.

$\S 11$. Toelichting; de adjuncties, die door verba worden geregeerd. $-\S 12$. Slot.

$\S 1$. Algemeene inleiding.

In alle wetenschappelijk denken, bovenal in de wijsbegeerte ontmoeten wij het streven naar het ,stelsel." Het stelsel is de afsluiting - wekt althans den schijn eener afsluiting - van een wetenschappelijk onderzoek. In haar stelsels ontmoet de wetenschap de kunst; en zoo kunnen we van een architectoniek der wetenschap spreken.

Door de behoefte aan het stelsel ontvangen indeeling en classificatie niet alleen de beteekenis eener voorbereiding van de wetenschappelijke verklaring, d. i. de rangschikking van alle bizonderheden onder het algemeene; zij krijgen een hoogere waarde tevens, zij geven aan de wetenschap den bevredigenden vorm van uiteenzetting.

Niet alleen in de vinding van algemeene wetten, maar ook in den telkens herhaalden opbouw van stelsels drukt zich de voortgang der wetenschap uit.

Bij de bestudeering der taal kan men zich ten eerste tot taak stellen: een taal, een ons aanvankelijk vreemde taal, te beheerschen; ons over die taal een macht te verzekeren, die de vertrouwdheid nabij komt, waarmede we ons bewegen in onze moedertaal. Hoe die heerschappij dan verkregen wordt, is onverschillig; een onbewust gevormd taalgevoel kan hooger waarde hebben dan bewuste waarneming en kennis.

Maar vat men de taak der taalstudie eenmaal theoretisch op, dan zullen ook de eischen van alle wetenschappelijk denken zich doen gelden: de behoefte aan verklaring, en de behoefte aan het stelsel, d. w. z. de rangschikking der stof naar beginselen.

Nu kan men de taal beschouwen als een klanken-reeks, als een physiologisch-psychologisch proces, men kan en moet haar bovendien beschouwen in verband met hetgeen ik thans kortheidshalve wil noemen: de gedachte. Zonder op de afscheiding - en daarmede tevens op de overgangen - tusschen beide gebieden in te gaan, mogen we zeggen: het eerste gebied behoort tot de klankleer, het tweede tot vormleer en syntaxis. Het verband tusschen vormleer en syntaxis is dus nauwer dan dat tusschen vormleer en klankleer.

Zeggen we: vormleer en syntaxis beschrijven het verband tusschen taal en gedachte, dan hebben we ons eigenlijk onvolledig uitgedrukt; immers het verband tusschen het enkele woord en zijn beteekenis wordt daarbij ter zijde geschoven. Doch zoowel hier, als elders, moet ik mij beperken, en dus vaak mij min of meer onvolledig en onnauwkeurig uitdrukken.

De vormleer beschrijft de vorm-veranderingen der woorden: het gebruik van affixen (suffixen, praefixen, infixen) en van klanksymboliek (ablaut). 
Ook zou men er toe kunnen rekenen de leer der woord-volgorde. Rekent men er alleen toe de leer der affixen en der klank-symboliek, dan zal bij de beschrijving van sommige talen dit geheele onderwerp wegvallen.

De syntaxis - al of niet te zamen met de vormleer - onderzoekt het verband tusschen twee verbanden, en wel tusschen 1 . het verband tusschen de woorden, afhankelijk van hun vormverandering en rangschikking, en 2 . het verband tusschen de denkbeelden, welk verband het wezen van de ,gedachte" uitmaakt.

Aan deze syntaxis kunnen we derhalve tweeërlei vorm geven, al naar de richting, waarin het onderzoek zich beweegt; vragen we ons af, hoe wordt het verband der denkbeelden uitgedrukt in het verband der woorden, dan zullen we dat de analytische methode der syntaxis noemen; gaan we in onze beschrijving daarentegen uit van de vormverandering der woorden en hun rangschikking, om vandaar te komen tot de gedachte, dan zullen we spreken van de synthetische methode der syntaxis; eveneens zullen we hoofdstukken, waarin we de beteekenis vaststellen van woorden met zeer algemeenen inhoud als: voorzetsels, of werkwoorden van modaliteit, tot de synthetische syntaxis kunnen rekenen.

Bij dit alles bedenke men, dat het verstand het recht heeft en de plicht, om gewelddadig van elkander te scheiden, wat inderdaad hoogst ingewikkeld met elkander samengeweven is.

Ook is deze studie meer bedoeld als een opwekking tot verder onderzoek dan als een beslissing in tal van netelige kwesties.

§ 2. De a anleiding tot de volgende beschouwingen.

$\mathrm{Nu}$ heeft John Ries in zijn verhandeling Was ist Syntax betoogd, dat de beide bovengenoemde vormen van syntactische taalbeschrijving, de zoogenaamde analytische en synthetische methodes gelijkelijk onbevredigend zijn, en dat er dus een derde, een eigenlijk-syntactische, een Riesiaansche methode noodig is, die ze vervangt. Hij grondde zijn betoog op de ernstige. tekortkomingen in de systematiek, die we in bekende grammatische werken, - zooals de Latijnsche syntaxis van Madvig of de Grieksche syntaxis van Kühner - herhaaldelijk kunnen aantreffen, gebreken, die naar de meening. van Ries uit de gevolgde methode zouden voortvloeier.

Het denkbeeld, dat aan Ries' beschouwing ten grondslag ligt, wil ik door de twee volgende Latijnsche voorbeelden toelichten. Beschouwen wij een zin als: pueri canunt, dan heeft de numerus van canunt alleen een syntactische, een "samenbindende" beteekenis, terwijl de numerus van pueri uit den zin zelf heenwijst naar het gedachte-object, dus niet zoozeer een syntactische, dan wel een semasiologische beteekenis heeft. Eveneens kunnen wij ten aanzien van een woordverbinding als: avis ocior vento opmerken, dat het vooral de comparatie-vorm acior is, die in dit geval uit den zin uitwijst en ons aan een objectief graadverschil doet denken, terwijl daarentegen de ablatief-vorm vento veeleer van grammatisch-verbindenden, dus van syntactischen aard is. We kunnen derhalve de betrekkingen, door woorden en woordvormen uitgedrukt, onderscheiden in syntactische en semasiologische; 
de bespreking der eerste zou in de syntaxis thuis behooren, die der tweede in de semasiologie. Syntaxis zou bijgevolg moeten zijn: de leer der woordverbindingen.

Deze opvatting van syntaxis als leer der woordverbindingen wordt ook gehuldigd door F. Holthausen (in zijn Altsächsisches Elementarbuch), die in beginsel de volgende vormen van woordverbindingen onderscheidt: 1. verbinding door een (niet-congrueerenden) casus; 2 . door een onveranderlijk nomen verbale (infinitivus); 3 . door voorzetsels; 4 . door voegwoorden (nevenschikking van deelen van den enkelvoudigen zin, etc.); 5. door congruentie.

Hoezeer ik deze classificatie der verbindingsmiddelen en de verdere groepeering van Holthausen's syntactische aanteekeningen waardeer, ben ik het toch in de hoofdzaak met Ries oneens. Vooreerst is het engere gebruik van den term syntaxis, alleen op grond van de etymologie van het woord, ongewenscht, ook al erkent men gaarne de juistheid van de verdeeling der grammatische betrekkingen in syntactische en overwegend-semasiologische; en al meent men de laatste in een afzonderlijk hoofdstuk te moeten behandelen. Maar vooral betwijfel ik de bewering, dat nu ook de onderscheiding van de analytische en synthetische methode zou vervallen; immers wat Holthausen in overeenstemming met zijn leer ons biedt, is niets anders dan een gewijzigde uitgave van de synthetische methode. Nog altijd lijkt mij juist de opvatting van den Sinoloog G. von der Gabelentz, volgens welke men de taal in verband met haar inhoud op tweeërlei wijze kan beschouwen, of in de richting van gedachte naar taal, of omgekeerd. $M$. a. w. de tekortkomingen, door Ries in verschillende grammatica's ten opzichte van de systematiek aangewezen, zijn niet noodzakelijk uitvloeisels der gevolgde methodes.

\section{\$3. Innerlijke taalvorm.}

Allereerst moet ik over het verband tusschen taal en gedachte nog een algemeene opmerking maken, en wel deze: dat volken, die verschillende talen spreken, niet alleen verschillend spreken, maar in zekeren zin ook verschillend denken. Ofschoon dus de algemeene psychische wetten voor alle denken dezelfde blijven, kan de structuur der gedachte toch onderling verschillen. Vertaalt men dus, dan is de gang niet: uit taal A tot de gedachte, en vandaar tot taal $B$; maar veeleer van taal $A$ tot gedachte $A$; en vandaar tot de aequivalente gedachte $B$, waarop dan vervolgens de taal $B$ volgt. Dit feit werd door Von Humboldt, den grondlegger der ethnologische taalwetenschap genoemd: de innerlijke taalvorm. Zulk een verschil in innerlijken taalvorm kan bijv. afhangen van de meerdere of mindere mate, waarin de sprekers eener taal uit het verband de onuitgesproken betrekkingen plegen aan te vullen. Zoo zullen er talen zijn, die, indien er geen gevaar voor dubbelzinnigheid bestaat, den numerus van het substantief onuitgedrukt laten; zoo zullen sommige talen er eerder dan andere toe overgaan, het progressieve aspect eener handeling in woorden vast te leggen. Opvallender nog wordt het verschil, indien een taal het onderscheid tusschen activum en passivum niet kent, indien dus onverschillig of volgens de opvatting eener andere taal de zaak een werking uitoefent dan wel ondergaat, steeds het nomen in een en denzelfden vorm aan den gelijken werkwoordsvorm wordt toe- 
gevoegd, terwijl eerst dan een onderscheiding wordt aangebracht door middel van een partikel, wanneer twee grammatische zelfstandigheden (zaken of personen) bij de werking betrokken zijn in verschillende causale betrekking.

Uit dezen nauwen samenhang van taal en gedachte volgt, dat de synthetische en analytische taalbeschrijving nimmer streng te scheiden zijn: beschrijft men een taal bijv. synthetisch, d. w. z. morphologisch-syntactisch, dan is het noodig, dat de beschrijver zich ook rekenschap geeft - hetgeen veelal onvoldoende het geval is - van de relatie-categorieën, die zich in de gedachte-structuur laten verwachten. En omgekeerd, wie de syntactische feiten in hoofdzaak analytisch groepeert, heeft natuurlijk met de morphologie rekening te houden.

\section{§4. De hoofdstukken der syntaxis.}

Bij de studie van het Sanskrit is de Syntax van Speyer, in 1886 gepubliceerd, nog altijd een der meest gebruikte handboeken. Naar zijn opzet is dit werk eclectisch; het is met takt in elkaar gezet en daardoor een handig leerboek, maar stelt dengene, die een beginselgetrouwe systematiek verlangt, telkens teleur.

Zoo heeft de vraag mij vaak beziggehouden, in hoeverre onderwerpen, door Speyer synthetisch behandeld, analytisch beschouwd konden worden, en omgekeerd. $\mathrm{Na}$ verscheiden mislukte pogingen ben $\mathrm{ik}$ ten slotte tot een schema gekomen, waarnaar (meen ik) de feiten zich duidelijk en ongedwongen laten rangschikken en waarbij tevens de beginselen der indeeling niet uit het $00 \mathrm{~g}$ worden verloren. Volgens dit schema vervait de syntaxis in zes hoofdstukken:

1. de analytische behandeling van den enkelvoudigen zin, (in het volgende uitvoeriger te bespreken);

2. de synthetische samenvatting daarvan;

3. de semasiologische syntaxis, bevattende: $a$. de bespreking van de woordsoort-verschuiving (substantiveering van adjectiva etc.); $b$. de beschouwing van semasiologisch-syntactische betrekkingen, als: numerus van het substantief; de comparatie-vormen; genus, tempus en modus van het werkwoord, enz.; $c$. de leer der woordbeteekenissen (bijv. de beteekenis der verbale praefixen) en der veranderingen in de woordbeteekenissen, voorzoover dit alles voor de syntaxis van belang is;

4. de analytische beschouwing van co- en subordinatie;

5. de synthetische samenvatting daarvan;

6. de leer der woord- en zinvolgorde.

$\S 5$. De categorieënleer.

De voornaamste moeilijkheid levert op: het eerste dezer hoofdstukken. Immers bij synthetische talen als Latijn en Sanskrit pleegt men de constructie van den enkelvoudigen zin grootendeels als "leer der naamvallen" te behandelen, terwijl men in de grammatica's van analytische talen als Nederlandsch en Engelsch voor het gebruik der voorzetsels gewoonlijk naar het woordenboek verwijst, dus stilzwijgend eveneens voor een groot gedeelte de synthetische methode volgt. En in 't algemeen is de morphologische methode van syntaxis het meest in aanzien bij de wetenschappelijke taal- 
onderzoekers, die ervan terugschrikken zich met de categorieën-leer der wijsbegeerte bezig te houden, en trouwens de teleurstellende ervaringen van oudere geslachten van geleerden en hun misbruik van de stelsels van Kant en Hegel voor oogen hebben.

Doch al heeft de wijsgeerige categorieën-leer haar moeilijkheden en onzekerheden, zonder een inzicht in de gedachte-structuur is zelfs een bevredigende synthetische syntaxis niet mogelijk. En bovendien wat, buiten het wetenschappelijke taalonderzoek in engeren zin om, door onderwijsmannen op het gebied der analytische syntaxis werd geleverd, - ik wil hier slechts noemen de Nederlandsche Spraakkunst van L. Leopold en Joh. A. Leopold, waarvan het eerste deel in 1896 verscheen, - bevat vaak zooveel goeds, dat het waarlijk tijd wordt, dat ook de beoefenaars der taalwetenschap, zooals deze zich om de universiteits-studiën groepeert, eens van hun schrik bekomen.

Het probleem, dat $\mathbf{i k}$ mij om die reden stelde, luidde: hoe laat zich de leer van den enkelvoudigen zin, bijv. voor synthetische talen als Latijn en Sanskrit, analytisch behandelen; dus hoe laat zich hier de stof ongedwongen groepeeren in verband met de functies in den zin: subject, praedicaat, attribuut (adnominale bepaling), adjunctie en adjunctioneel attribuut. Bij het onderzoek bleek mij, dat de voornaamste moeilijkheid gelegen is in de scheiding tusschen de bijwoordelijke bepalingen in engeren zin en de voorwerpen; deze splitsing heeft niet die overwegende beteekenis, welke men eraan toeschrijft en behoort naar het tweede plan te worden verschoven.

De allereerste verdeeling dus der adjuncties, besloot $\mathrm{ik}$, moet berusten op den aard der betrekkingen, er door uitgedrukt; derhalve ontleend worden aan de categorieën-leer der wijsbegeerte. $M$. a. w., de teleurstellingen, door de vroegere taalwetenschap opgedaan, zijn te wijten aan de toepassing, en niet aan de beginselen.

De classificatie, die ik ten slotte aannam, is dan ook hoofdzakelijk aan Chr. Sigwart ${ }^{1}$ ) en W. Windelband ontleend en luidt als volgt:

1. adjuncties van ruimtelijke en temporeele betrekkingen;

2. adjuncties van oorzakelijkheid en samenhang;

3. adjuncties van reflectieve betrekkingen, d. w. z. betrekkingen, die een meer abstract of subjectief karakter hebben, betrekkingen, waarbij de geest identificeert, onderscheidt, vergelijkt, telt, meet, samenvoegt, afzondert, tot soorten vereenigt, enz.;

4. adjuncties van modaliteit, d. w. z. den aard der betrekking, waarin de gedachte als een geheel staat tot de werkelijkheid, of omgekeerd de werkelijkheid tot de gedachte, dus ook tot den denkenden en handelenden mensch.

\section{$\S 6$. Geen scherpe grenzen tusschen de categorieền.}

De moeilijkheid, om deze categorieèn-leer in de grammatica toe te passen vindt haar grond in het volkomen ontbreken van grenzen tusschen de categorieën. Een begrip als afstand bijv. is eenerzijds een ruimtelijke relatie, anderzijds een reflectieve, waarbij de geest vergelijkt en telt. De regels,

1) Logik I $\$ 6$, Tübingen 1904. Sigwart's classificatie houdt nauw verband met Kant's wijsbegeerte en indirect dus ook met Heger's categorieën-leer. 
der syllogistiek behooren zoowel tot de reflectieve als de oorzakelijke betrekkingen.

Troūwens het bezwaar is reeds herhaaldelijk behandeld; zeer aantrekkelijk en aanschouwelijk in de bovengenoemde Nederlandsche Spraakkunst, van $L$. en Joh. A. Leopold.

Aangezien formeele categorieën als nominatieven, genetieven, enz. onmiddellijk zijn te onderscheiden, zal dus een synthetische syntaxis van den enkelvoudigen volzin gemakkelijker, maar tevens oppervlakkiger zijn dan een analytische behandeling van dat onderwerp.

\section{§ 7. De categorie der oorzakelijkheid.}

Een andere moeilijkheid in de toepassing der categorieën-leer wordt veroorzaakt door de onjuiste beschouwingen, die over het causaliteits-begrip gangbaar zijn. Dit begrip wordt namelijk door de wijsgeeren bij voorkeur behandeld in verband met de natuurwetenschap; en de grammatica heeft daarvan de slechte gevolgen ondervonden. Zoo kent men daar de oorzakelijkheid vooral als: oorzaak en gevolg, doel en middel, onderstelling en gevolgtrekking, ontoereikende oorzaak en uitblijvend gevolg. Het is evenwel niet de vraag, hoe de natuurwetenschap het oorzakelijkheids-begrip opvat, maar wel hoe onontwikkelde sprekers de causaliteit begrijpen en in vroegere taalperioden begrepen hebben. Een kennis van de magische opvatting van het natuurverband, zooals wij die bij primitieve volkeren aantreffen, is voor den taalonderzoeker van onmiddellijker beteekenis dan bijv. de theorieën, die Schopenhauer of ten onzent G. Heymans over het oorzakelijkheids-begrip in het licht hebben gezonden.

Het begrip oorzakelijkheid omvat dus voor den taalonderzoeker vèel meer dan de logische relatie tusschen onderstelling en haar noodzakelijk gevolg, of het verband tusschen een verandering $p$ in een object $A$ en de daardoor veroorzaakte verandering $q$ in een object $B$.

Het begrip oorzakelijkheid omvat voor hen ook de stof, waaruit een voorwerp wordt vervaardigd; het voorwerp, dat door de bewerking verkregen of veranderd wordt. En nog veel meer; naar de beschouwingen van Chr. Sigwart zou in een zinnetje als: $i k$ zie de zon, de betrekking tusschen dit natuurvoorwerp en den aanschouwer van modalen aard zijn; immers plaatsen we ons, met de taal, op naief-realistisch standpunt, dan zou de zon in het heelal zich spiegelen in mijn bewustzijn, en door die spiegeling zou er een voorstelling, een representatief beeld in mijn bewustzijn ontstaan. Betrekkingen nu tusschen den geest en de buitenwereld heeten modaal; derhalve is ook de betrekking tusschen waarnemer en waargenomen voorwerp van modalen aard. De opvatting der taal wijst, hoewel evenzeer naïef-realistisch, toch in andere richting. Uitdrukkingen als: „ik kijk naar de zon”, „ik kijk uit het venster", ik zie de laan in", ,ik kijk het boek in", „,ik luister door het sleutelgat" wijzen op een nog primitievere aanschouwingswijze ten tijde van het ontstaan dezer uitdrukkingen dan Sigwart hier voor de taal aanneemt. Bij het hooren en zien dan hebben er bewegingen van stralen plaats; en deze oog- .en oorstralen, geholpen door het licht of de stilte, grijpen het voorwerp, even goed als onze handen. En evenals we naar een voorwerp 
grijpen kunnen, maar ook met sluiting der handen het voorwerp zelf grijpen, zoo kijkt soms het oog naar het voorwerp en een andere keer ziet het dit; in het eene geval is dus de beweging der oog-stralen gedacht als progressief, in het tweede geval als effectief.

Beschouwen we nog eens nader het geval „ik grijp een plank" en vergelijken we het daartoe met den zin ,ilk schaaf de plank." Hierbij valt al dadelijk op te merken, dat de passieve vorm „de plank wordt geschaafd" meer voor de hand ligt dan "de plank wordt gegrepen"; de laatste uitdrukking maakt dus den indruk van een secundaire uitbreiding van de passieve constructie, een uitbreiding, die aan den wensch naar ondubbelzinnigheid of nadrukkelijkheid of aan andere motieven te danken kan zijn. En dat is begrijpelijk: de plank, die geschaafd wordt, verkrijgt een nieuwe eigenschap: wordt glad; de causale inwerking is dus onmiddellijk zichtbaar. De plank, die we grepen, daarentegen ondervindt daarvan geen zichtbaren invloed; wel komen plank eh persoon, die grijpt, tot elkaar in een ruimtelijke betrekking, die ertoe leiden kan, dat de beweging van den eene door de beweging van den andere wordt gedeeld; de causale relatie is derhalve hier van latenten aard.

Ook in een zin als: „de boer heeft zeven koeien" hebben wij met zulk een latente causale betrekking te doen. Op grond daarvan melkt hij zijn koeien en verkoopt er de melk van, of brengt ze naar den slager en ontvangt de betaling.

In een zin als ,het meisje heeft een kleur", is deze latente causale relatie aanvaard als een metaphorische uitdrukking voor de betrekking van inhaerentie. Eveneens in „Nederland heeft elf provincies" wordt het geheel gedacht als de bezitter, d. w. z. de eventueele beschikker over zijn deelen.

Beschouwen we wederom een ander geval: ,ik reis met een vriend"; in de grammatica noemt men dat een adjunctie van omstandigheid; en daar is niets tegen; evenwel ook omstandigheden zijn causale betrekkingen in ruimen zin: het samenreizen stelt in staat tot wederzijdsche hulp, gezelligheid enz.

Ook de adjuncties van wijze - voorzoover ze geen reflectieve betrekkingen uitdrukken - laten zich onder de adjuncties van „oorzakelijkheid en samenhang" rangschikken.

\section{$\S 8$. De categorie der modaliteit.}

Terwijl ik de categorie der causaliteit vooral besprak ten opzichte van de causale adjuncties, wensch ik de categorie der modaliteit hier te beschouwen in haar verband met de semasiologisch-syntactische betrekkingen, dus met hetgeen ik noemde (in $\S 3$ ) het derde hoofdstuk der syntaxis.

Is het niet wenschelijk, wilde ik hier vragen, om, ter zijde van de morphologische modi van het werkwoord, de volgende schakeeringen in de modaliteit der gedachte te onderscheiden:

I. Factische modaliteit: verhaal, beschrijving, algemeene bewering;

II. Theoretische modaliteit, en wel „afwegende" modaliteit (mogelijk, onmogelijk, waarschijnlijk, noodzakelijk), en ,verwerpende" modaliteit (o. a. voorkomende in de conditioneele perioden van irrealiteit); 
III. Practische modaliteit; vooreerst de modaliteit, waarbij de vervulling eener gedachte afhankelijk is van een „wilsverhouding", (naar Herbart's terminologie), waarbij dus de eene mensch den anderen beveelt of gehoorzaamt, hem raad geeft of om raad vraagt; dan de modaliteit, waarbij de handelende zich gebonden gevoelt aan plicht of verplichtingen; ten slotte de uiting van een wensch, een klacht, van verwijt en berouw.

§9. De semasiologische classificatie der werkwoorden.

Nadat ik dan vastgesteld had, dat de adjuncties zich tot vier hoofdgroepen laten brengen: ruimtelijke met temporeele, causale, reflectieve en modale, kwam het er op aan een tweede beginsel voor de onderverdeeling te kiezen. Hier dan mocht de scheiding tusschen object en niet-object, tusschen geregeerdc en vrije adjunctie ter sprake komen. Derhalve stelde ik als vraag: welke semasiologische groepen van werkwoorden (en adjectieven) leiden er ons krachtens haar beteekenis toe, juist de adjunctie van één bepaalde categorie te verwachten? Zooals de werkwoorden, die een technische verrichting beteekenen, natuurlijkerwijze of een adjunctie van het materiaal, of van ' $t$ bewerkte voorwerp, of van het voortbrengsel, in 't algemeen een adjunctie van causaliteit tot zich trekken, zoo zou het ook kunnen zijn, dat andere semasiologische groepen eveneens vaste kenmerkende adjuncties met zich brengen. Alvorens verder te gaan, was het dus noodig een semasiologische indeeling van de regeerende woorden, van verba en relatieve adjectiva te beproeven. $\mathrm{Nu}$ bevatten feitelijk, ofschoon onopzettelijk en ongeordend, ook de synthetische leerboeken dergelijke groepeeringen. Er was alleen een samenvatting noodig. Op deze wijze kwam ik voor de werkwoorden tot drie hoofdgroepen: 1. werkwoorden van algemeene beschrijving, in 't bizonder natuurbeschrijving; (derhalve werkwoorden van existentie, rust en beweging, van qualitatieven toestand en van toestands-verandering; van vervaardiging en vernietiging, van plaatsing en bewegingsveroorzaking, van causale beinvloeding der qualitatieve toestanden); 2. psychologische werkwoorden, (dus werkwoorden van gewaarwordings- en gevoelsoorzaak, werkwoorden van innerlijke psychische processen, werkwoorden van handelingen en van toestanden, causaal in verband staande met de handelingen); 3 . werkwoorden van relatie (tijd, oorzakelijkheid, modaliteit).

$\S 10$. Geen scherpe grenzen tusschen de semasiologische groepen.

Onmiddellijk deed zich hier de moeilijkheid voor: er bestaan geen vaste grenzen tusschen de semasiologische groepen, en bovendien veranderen de woorden zoo onophoudelijk van beteekenis, dat telkens een en hetzelfde woord tot meerdere groepen zal behonren. Om deze moeilijkheid te ontgaan, beproefde ik de volgende beginselen:

a. Tracht de oorspronkelijke beteekenis van het woord te vinden en onderzoek, of de ook later geldig gebleven constructie verklaard kan worden uit een oorspronkelijk metaphorisch gebruik van het woord. Zoo zullen begrijpen en vatten, psychologisch gebruikt, een zelfde adjunctie regeeren, als begrijpen en vatten in letterlijken zin deden.

b. Hebben wellicht nieuwe idee-associaties de oude constructie verdron- 
gen? Zoo beteekent in het Sanskrit ni-vedayati „he causes somebody (accus.) to know"; het werkwoord is immers een causativum. en vereischt als zoodanig dus den accusativus van den persoon, dien men een bepaalde handeling laat verrichten, of dien men in een bepaalden toestand doet verkeeren. Maar de accusativus maakte plaats voor een dativus; het werkwoord werd dus blijkbaar niet langer als een causativum gevoeld, maar als synoniem met „meedeelen, zeggen", begon dus te beteekenen een „overdracht van kennis".

c. Rangschik de woorden onder rubrieken en regels naar de beteekenis, die overheerscht in een bepaalde constructie.

Opm. Ter toelichting van een en ander wil ik beschouwen de volgende zinnetjes: 1 . hij begon midden in zijn slaap te roepen; 2 . hij riep: hulp, hulp; 3. hij riep om water; 4 . hij riep mij. In het eerste zinnetje is er geen sprake van bedoelingen bij het roepen, noch wordt er op gevolgen gelet, het roepen is een in zich zelf afgesloten verrichting. In het tweede worden de woordklanken: „hulp, hulp," voorgesteld als het voortbrengsel van het roepen. In het derde is "roepen om", zooveel als: „met luide stem vragen om"; het woord drukt dus een verlangen uit, of liever de uiting van een verlangen. In het vierde gaat het eveneens om een verlangen, doch een tweede persoon is er bij betrokken, een persoon, dien men beveelt nader te komen. In overeenstemming met beginsel $c$ zullen dus de constructies van dit eene werkwoord onder verschillende rubrieken besproken worden.

§ 11. Toelichting; de adjuncties, die door verba worden geregeerd.

Ter toelichting van het een en ander laat ik hier het schema volgen, waarnaar ik de adjuncties, in het Sanskrit door verba geregeerd, heb trachten te groepeeren: daarbij valt op te merken, dat ik voor de nog verder gaande verdeeling der allerlaatste aldus verkregen groepen gebruik heb gemaakt van morphologische beginselen (vgl. Holthausen's classificatie daarvan; boven $\S 1$ ).

Geregeerde adjuncties van plaats en tijd. Deze kunnen zich voordoen bij werkwoorden, die in hun beteekenis een locale of temporeele betrekking insluiten; dus 0 . a. werkwoorden van rust in bepaalden stand ten opzichte van de rustplaats; van beweging, in richting bepaald ten opzichte van een voorwerp; van plaatsing enz.; van duren en vertoeven.

Geregeerde adjuncties van oorzakelijkheiden samenhang:

a. bij niet-af gel ei de werkwoorden (dus niet: passiva of causativa),

1. bij werkwoorden, wier beteekenis inhoudt een physische oorzakelijkheid of algemeenen causalen samenhang; dus bij werkwoorden van vervaardiging en vernietiging, van plaatsing en bewegingsveroorzaking, en van bewerking;

2. bij werkwoorden van gewaarwordings- en gevoelsoorzaak; - bijv. schijnen, behagen. Daarbij sluiten zich, als een tweede groep, de onpersoonlijke werkwoorden van gemoedsaandoening aan. Daar deze twee groepen vaak in elkaar overvloeien, heeft men in de leer der subordinatie vaak moeite subjects-bijzin en adjunctioneelen bijzin van elkander te onderscheiden;

3. bij werkwoorden van innerlijken psychischen toestand, - d. w. z. 
psychische toestanden, die nog in ons innerlijk blijven besloten, en zich niet door woord of daad trachten te uiten; derhalve o. a. werkwoorden van waarneming en herinnering, van gedachte en oordeel, van gemoedsaandoening en gezindheid;

4. bij werkwoorden van meedeeling betreffende den innerlijken psychischen toestand; - buiten de constructies, door werkwoorden van de vorige groep vereischt, vindt men hier nog een adjunctie van den persoon, tot wien de spreker zich richt. Geeft de spreker uiting aan zijn gezindheid, dan zal de persoon tot wien men spreekt en de persoon voor wien men de gezindheid gevoelt, in den regel dezelfde zijn;

5. bij werkwoorden van den wil (begeeren, willen, handelen) en van interne oorzakelijke betrekking, $\longrightarrow \mathrm{d}$. w. z. een zich uitende of verborgen oorzakelijke betrekking, waarin de persoon als uitgangspunt is gedacht en die zijn eventueele handelingen bepaalt. Het aantal dezer werkwoorden is zeer groot en hun rangschikking moeilijk; het volgende schema heb ik als leiddraad trachten te volgen:

5a. de wil of interne oorzakelijke betrekking is gericht op zaken (begeeren, verkrijgen, verliezen, bezitten);

5b. de wil of interne oorzakelijke betrekking is gericht op een tweeden persoon (vleien, gehoorzamen, regeeren enz.);

5c. de wil is gericht op een verdere werkzaamheid van den persoon zelf (doen, nalaten, voorbereiden enz.); voor de werkwoorden van interne oorzakelijke betrekking zie groep 8 ;

$5 d$. de wil of interne relatie is gericht op zaken èn personen, dus rubriek $a+b$ (werkwoorden van bezits-overdracht en schuldig zijn);

enzoovoorts.

Voorzoover bij deze werkwoorden een tweede volgende of bedoelde werkzaamheid voorkomt, kunnen we daarbij constructies verwachten met een infinitivus, of casus van een nomen actionis.

6. bij werkwoorden, uitdrukkende een causale of latent-causale relatie tusschen persoon en zaak, welke relatie verband houdt met een mogelijke handeling van den persoon, maar in welke relatie de zaak als uitgangspunt is gedacht (behooren aan, ontbreken, enz.);

7. bij de werkwoorden van staan, zitten, zich bevinden. - Bij deze werkwoorden kan een adjunctie voorkomen, die uitdrukt een werkzaamheid, door den persoon zelf gelijktijdig verricht; vgl. de Nederlandsche uitdrukkingen: ik lig te slapen, ik zit te schrijven, ik sta te oreeren, ik loop te zingen. Het Sanskrit gebruikt voor deze ,adjunctie van de gelijktijdige werkzaamheid" het zoogenaamde absolutivum, terwijl er, evenals in de genoemde Nederlandsche uitdrukkingen, een soort van samengroeiing plaats vindt der praedicaats-deelen, met semasiologische zwaartepunts-verplaatsing;

8. bij werkwoorden, beteekenende een causale of latent-causale relatie, welke gedacht wordt als zetelende in het subject van den zin en waaruit de hoofdwerking al of niet opzettelijk voortvloeit of voort kan vloeien; - derhalve werkwoorden als: kunnen, moeten, mogen, enz. Deze werkwoorden regeeren den infinitivus of een casus van een nomen actionis. Door semasiologische ontwikkeling kan met behoud van de constructie de causale re- 
latie in een temporeele of modale overgaan; bijv.: ,ik vang aan te spreken”, d. w. 2. oorspronkelijk; ,ik maak aanstalten, of ik maak mij gereed om te spreken"; "loqui incipio"; Skr. „vaditum ārambhe”. Ook bij deze werkwoorden heeft samengroeiing plaats der praedicaats-deelen, gepaard met semasiologische zwaartepunts-verplaatsing.

b. bij verba passiva;

c. bij verba causativa.

Geregeerde adjuncties van reflectieve relaties; - deze zijn te verwachten bij werkwọorden, wier beteekenis een reflectieve betrekking inhoudt, bijv.: gelijken op.

\section{§ 12. Slot.}

De waarde van bovenstaande beschouwingen zal eerst blijken uit haar toepassing; eerst dan kan men er ten volle over ourdeelen, of de gegeven indeeling inderdaad een ongedwongen en duidelijke behandeling der stof mogelijk maakt, en vooral ook, of de verdere verwachtingen, die ik ervan koester, zullen vervuld worden. Binnen niet te langen tijd hoop ik dan ook het uiteengezette schema aan de gegevens van het Sanskrit volledig te toetsen.

Toch zou ik reeds thans daaraan iets willen toevoegen. Terwijl in de physiologisch-psychologische studie reeds een beperkte stof tot belangwekkende resultaten kan leiden, zal het eerst dan mogelijk zijn aan de syntaxis het karakter eener aetiologie te geven, wanneer men zijn studie niet uitsluitend beperkt tot talen van éen genealogisch verwante groep. Voor den Sanskritist zal het Tibetaansch of Drawidisch het eerst in aanmerking komen, voor den Romanist het Baskisch, voor den Slavist het Finsch en Hongaarsch, maar in ieder geval de ethnologische taalstudie heeft recht op veel grootere bejangstelling dan haar tot nu toe ten deel is gevallen.

Doorn.

B. FADDEGON.

\section{ANDRÉ CHÉNIER ET BION.}

I.

\section{„La Jeune Tarentine" et „le Chant funebre en l'honneur d'Adonis".}

Bion de Smyrne, le disciple et peut-être aussi le contemporain de Théocrite, était un poète harmonieux et un artiste délicat; il excellait à chanter avec esprit et avec gout l'amour mondain, élégant et superficiel. Deux ou trois de ses idylles sont de tout petits, mais de purs chefs-d'œuvre, qui ont souvent provoqué l'admiration des poètes modernes; elles ont dû rappeler au poète des Bucoliques les épigrammes qu'il aimait à traduire de l'Anthologie de Brunck. Outre une quinzaine d'idylles et de petits fragments nous possédons de Bion un poème d'une centaine de vers sur la mort d'Adonis; c'est son principal titre de gloire auprès de la postérité. Ronsard l'a imité dans une élégie où sa mélancolie et sa tendresse s'allient à une grâce diffuse et nonchalante qui n'est pas sans charme: 